\title{
Marcos Históricos em Cristalografia
}

\author{
Maria João Romão*, Teresa Santos-Silva, Isabel Bento, Filipe Freire, Marino F.A. Santos, Ana Luísa Carvalho \\ UCIBIO, REQUIMTE, Departamento de Química, Faculdade de Ciências e Tecnologia, Universidade Nova de Lisboa \\ maria.romao@fct.unl.pt
}

\begin{abstract}
Milestones in Crystallography - Crystallography has been recognized as one of the pillars of the scientific knowledge, namely for understanding the nature of the materials that surround us. Nowadays, Crystallography is applied in many different areas, from the design of new drugs to the development of new materials. UNESCO, considering its impact in humankind, declared 2014 the International Year of Crystallography. In this paper we describe the most relevant milestones in Crystallography, since the XVIII century until the present day, highlighting the great importance of Crystallography to our current knowledge in a wide range of areas, from Physics to Chemistry and Biology.
\end{abstract}

A Cristalografia tem sido reconhecida como um dos pilares do conhecimento científico, permitindo compreender em detalhe a natureza dos materiais que nos rodeiam. Actualmente a sua aplicação estende-se a áreas muito diversas, desde o desenho de novos fármacos ao desenvolvimento de novos materiais. 2014 foi declarado pela UNESCO o Ano Internacional da Cristalografia tendo em conta o impacto que esta ciência tem na vida humana. Neste artigo é apresentada uma compilação de alguns marcos históricos relevantes em Cristalografia, desde o século XVIII até à actualidade, ilustrando a sua notável contribuição para o conhecimento actual em áreas muito diversas, desde a Física à Química e Biologia.

\section{INTRODUÇÃO}

São inúmeras as contribuições da Cristalografia para o progresso em diferentes áreas científicas como a Física, a Química, a Biologia, a Medicina ou a Ciência dos Materiais. Com o objectivo de ilustrar a importância da Cristalografia ao longo do tempo, compilámos neste artigo alguns dos marcos históricos mais relevantes. Tendo por inspiração um suplemento, editado pelo grupo Nature, no âmbito das celebrações do Ano Internacional da Cristalografia (AICr2014), intitulado Milestones in Crystallography [1], seleccionámos dezassete grandes descobertas ou avanços que são descritas por ordem (quase) cronológica desde o nascimento da Cristalografia até ao seu impacto na compreensão de fenómenos na Química e na Biologia. Os exemplos escolhidos vão desde os minerais e a simples molécula do benzeno até complexos macromoleculares como os vírus ou o ribossoma.

\section{A nATUREZA INTERNA DOS CRISTAIS}

Em 1781, Rene-Just Hauy, um padre parisiense, ao observar um lindíssimo cristal prismático de calcite, deixou-o cair acidentalmente, o qual se desfez em vários pedaços. Ao observar os fragmentos do cristal verificou que as fracturas haviam ocorrido ao longo de planos bem definidos, posteriormente designados por planos cristalográficos. Baseado na observação da morfologia dos cristais (Figura 1), Hauy propôs a existência de seis formas cristalinas e concluiu que os cristais deveriam ser resultantes de uma repetição de unidades a que chamou "molécules intégrantes" (células unitárias) [2]. O contratempo da queda do cristal aliado ao apurado espírito de observação de Hauy ajudou à compreensão de uma característica fundamental dos materiais cristalinos: a periodicidade.

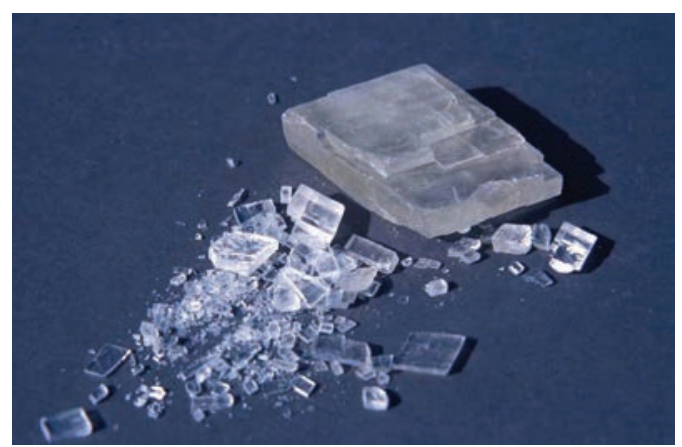

Figura 1 - Cristal de calcite e fragmentos formados por clivagem romboédrica

No entanto, este conceito era demasiado simples para explicar todas as propriedades dos cristais e subsistiam duas questões importantes por esclarecer: Qual a lista completa de operações de simetria que podem ocorrer num cristal? Qual a natureza das "molécules intégrantes" ou células unitárias? Em relação à primeira questão era claro que apenas os eixos de simetria rotacional 2, 3, 4 e 6 seriam consistentes com as propostas de Hauy e em 1830 Johann Hessel concluiu que aquela restrição conduziria a 32 possíveis classes cristalinas (grupos pontuais) [3]. Em relação à segunda questão faltava acrescentar ao conceito de célula unitária, o de rede cristalina que descreve um cristal como uma rede de pontos discretos gerados por determinadas operações de translação. Em 1850, August Bravais considerou esta noção para derivar o sistema de classificação para 14 possíveis redes cristalinas, as redes de Bravais [4]. No entanto, estas 14 redes não conseguiam ainda explicar todas as 32 classes cristalinas, pois faltava combinar translações com operações de rotação e de reflexão. Apenas alguns anos mais tarde foi possível, por aplicação da Teoria de Grupos, chegar à definição completa de todas as combi- 
nações possíveis de operações. Foram vários os cientistas envolvidos, tendo sido Arthur Schönflies quem, em 1891, publicou a lista completa dos 230 Grupos Espaciais [5]. Estes estão compilados nas Tabelas Internacionais de Cristalografia (Vol. A) e são uma referência para todos os cristalógrafos.

\section{Röntgen e a descoberta dos Raios-X}

Wilhelm Conrad Röntgen, Professor de Física na Universidade de Würzburg, descobriu no dia 8 de Novembro de 1895 "um novo tipo de radiação", como resultado de uma observação casual. Ao realizar experiências com tubos de raios catódicos observou que uma superfície fluorescente distante se apresentava iluminada. Ao investigar o que se passava descobriu que o impacto dos raios catódicos num tubo em vácuo gerava uma nova espécie de radiação invisível que tornava o ecrã fluorescente mesmo quando no seu percurso os raios tinham que atravessar objectos opacos (cartão, madeira, cobre, etc). Além disso observou que os raios podiam ser registados em chapas fotográficas (Figura 2). Na medida que a natureza dessa radiação era então desconhecida, Röntgen decidiu chamar-lhe raios-X. Logo a 28 de Dezembro do mesmo ano os resultados foram aceites para publicação nos Proceedings da Sociedade de Física Médica de Würzburg [6].

A notícia das observações de Röntgen espalhou-se muito rapidamente para a época de então tendo tido uma repercussão gigantesca a nível mundial. Em 1901, Röntgen recebeu o primeiro Prémio Nobel da Física pelo "reconhecimento dos serviços extraordinários prestados com a descoberta dos raios posteriormente designados com o seu nome”. Passados alguns anos, Max von Laue demonstrava que os raios-X são, tal como a luz visível, radiação electromagnética, diferindo apenas no respectivo comprimento de onda.

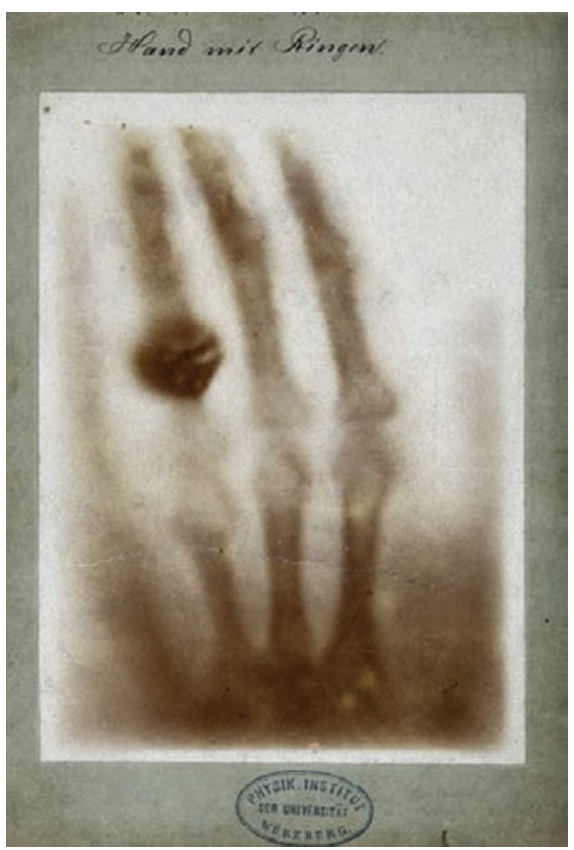

Figura 2 - Imagem de uma das primeiras fotografias de raios-X obtidas por Röntgen da mão esquerda da sua mulher (http://www.nobelprize.org/ nobel_prizes/physics/laureates/1901)

\section{A EXPERIÊNCIA DE VON LAUE}

Nos anos que se seguiram à descoberta dos raios- $\mathrm{X}$ foi estimado que o seu comprimento de onda seria da ordem de $0,5 \AA[7,8]$ mas persistia o debate acerca da verdadeira natureza dos mesmos. Teriam uma natureza corpuscular ou ondulatória? Em 1912, Max von Laue, Walter Friedrich e Paul Knipping realizaram a experiência crucial ao sujeitarem vários tipos de cristais $\left(\mathrm{ZnS}, \mathrm{Cu}_{2} \mathrm{SO}_{4}\right)$ à incidência de um feixe de raios-X. Ao colocarem uma chapa fotográfica por detrás do cristal observaram um registo directo dos raios-X demonstrando assim pela primeira vez a difracção de raios-X por uma rede cristalina (Figura 3) [9]. Estes resultados e a respectiva interpretação por von Laue [10] tiveram uma repercussão enorme no meio científico pois os padrões de interferência observados vinham comprovar a interpretação de que os raios-X eram ondas de radiação electromagnética. Além disso tiveram um grande impacto na comunidade de cristalografia pois as manchas de difracção bem definidas demonstravam que, nos cristais, os átomos estariam organizados numa rede espacial.

Max von Laue resolvia assim, com uma única experiência, duas questões que eram debatidas na comunidade científica no início dos anos 1900. Por um lado a compreensão da natureza misteriosa dos raios-X e por outro a demonstração da teoria do arranjo interno dos cristais em termos de uma rede regular de átomos. Em 1914 von Laue foi distinguido com o Prémio Nobel da Física pela "sua descoberta da difracção dos raios-X por cristais”.

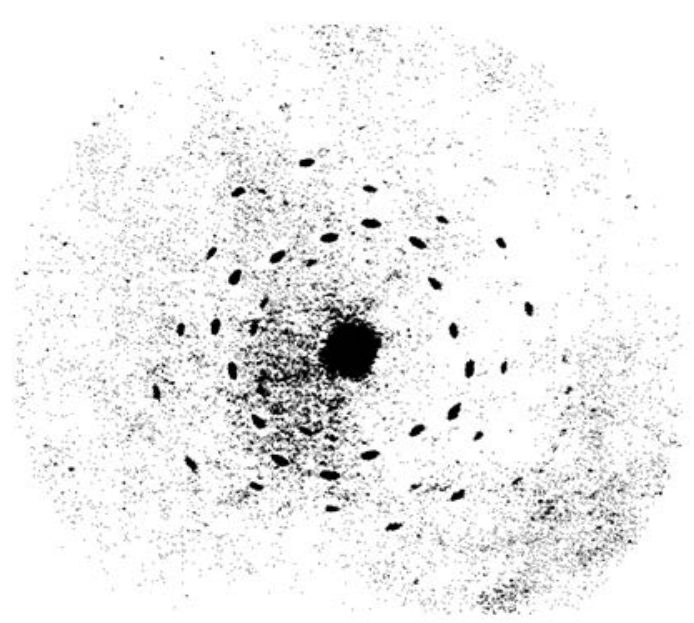

Figura 3 - Padrão de difracção por um cristal de ZnS depois de exposto aos raios-X (http://www.nobelprize.org/nobel_prizes/physics/laureates/1914/)

\section{A lei de Bragg}

Os resultados das experiências de Laue, Friedrich e Knipping [9] levaram à necessidade de uma teoria que interpretasse correctamente o fenómeno da difracção de raios-X. Segundo von Laue, sendo os raios-X radiação electromagnética com um comprimento de onda da ordem de grandeza das distâncias interatómicas, deveria haver um paralelismo com os padrões ópticos obtidos por incidência de luz visível numa rede de espaçamentos regulares [10]. 
Faltava contudo uma teoria que permitisse compreender as posições das reflexões assim como calcular as estruturas moleculares a partir dos padrões de difracção, o que veio a ser possível graças às descobertas de William Henry Bragg e do filho William Lawrence Bragg (Figura 4). Este último propôs um tratamento matemático em que a difracção resultaria da reflexão dos raios-X por planos paralelos sucessivos da rede cristalina. Segundo W.L. Bragg, os raios-X reflectidos por planos adjacentes, percorreriam diferentes distâncias tendo demonstrado que a difracção só ocorre quando a diferença da distância percorrida é igual a um múltiplo do comprimento de onda do feixe de raios-X [11,12]. Esta distância é, por sua vez, dependente do ângulo de incidência $(\theta)$ que se relaciona com o comprimento de onda $\lambda$, através da famosa lei de Bragg, $n \lambda=2 d \sin \theta$.

Para além do tratamento matemático foi também crucial o desenvolvimento do primeiro espectrómetro de raios-X [13] que permitiu a W.H. Bragg e W.L. Bragg detectarem os raios-X difractados a diferentes ângulos de incidência. Foi-lhes assim possível investigar cristais de diferentes composições e, recorrendo à lei de Bragg, resolver as primeiras estruturas cristalinas tais como as do cloreto de sódio ou do diamante [14-18]. Os métodos desenvolvidos por pai e filho para a análise das estruturas cristalinas levaram ao surgimento da cristalografia por raios-X e em 1915, W.H. Bragg e W.L. Bragg foram distinguidos com o Prémio Nobel da Física.

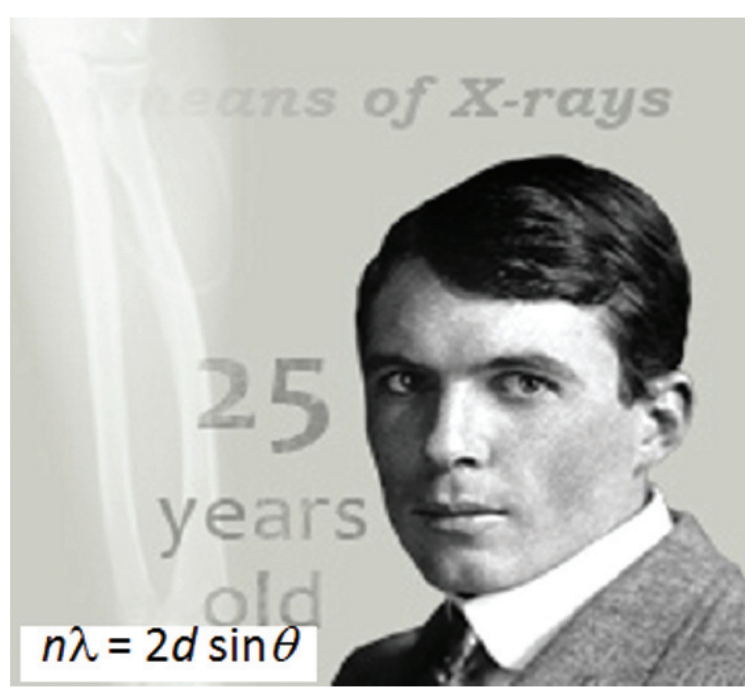

Figura 4 - William Lawrence Bragg com 25 anos quando recebeu o prémio Nobel da Física em 1915, juntamente com o seu Pai. É o mais jovem laureado Nobel em Química de sempre (http://www.nobelprize.org/nobel_prizes/physics/laureates/1915/)

\section{A estrutura das PRIMEIRAS MOLÉCULAS ORGÂNICAS}

No início do século XX, os químicos debatiam-se com os problemas de análise estrutural de moléculas, sendo as respectivas estruturas propostas com base em dedução lógica suportada experimentalmente. A validação dessas estruturas era em geral obtida indirectamente por síntese química. A descoberta da cristalografia de raios-X veio assim permitir a determinação directa das estruturas moleculares revolucionando a Química Orgânica. Nos anos 1920 ainda era duvidoso que as moléculas orgânicas mantivessem a sua identidade quando empacotadas num cristal. A primeira evidência de que tal era verdade surgiu em 1923 com a determinação da estrutura cristalina completa da hexametilenotetraamina $\left(\mathrm{C}_{6} \mathrm{H}_{12} \mathrm{~N}_{4}\right)$, levada a cabo independentemente por grupos de Berlim [19] e do Caltech [20], que confirmou a fórmula química do composto (Figura 5A).

Outro marco extremamente importante que se seguiu foi o trabalho notável de Kathleen Lonsdale, discípula de W.H. Bragg, que conseguiu decifrar um dos maiores mistérios da química de então: a estrutura do anel de benzeno. Apesar da proposta de Kékule em 1865 de que a estrutura do benzeno deveria conter um anel de seis membros com ligações simples e duplas alternadas, subsistiam dúvidas acerca da sua conformação e detalhes estruturais. K. Lonsdale escolheu estudar o hexametilbenzeno na medida em que, contrariamente ao benzeno ou muitos dos seus derivados, era sólido à temperatura ambiente. Após um trabalho exaustivo e persistente, em 1928 Kathleen conseguia provar a estrutura plana e regular do anel hexagonal do benzeno [21-23] o que teve uma repercussão enorme no futuro do conhecimento e análise de todos os compostos aromáticos.

Com estes desenvolvimentos pioneiros, as estruturas cristalinas passavam a ser utilizadas para validar a síntese química em vez do oposto.

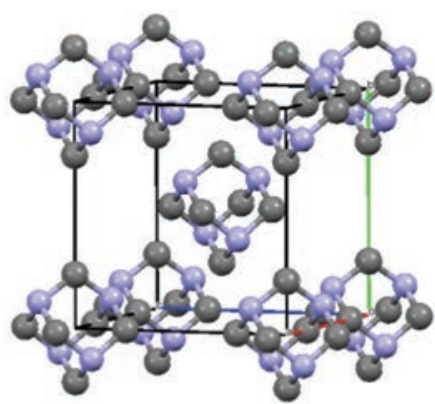

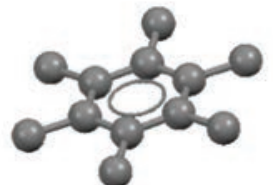

Figura 5 - A) Empacotamento cristalino da hexametilenotetraamina (átomos de $\mathrm{N}$ a azul e de $\mathrm{C}$ a cinzento) $\mathbf{B}$ ) estrutura do hexametilbenzeno

\section{A estrutura dos minerais}

Até à descoberta da difracção de raios-X, a análise de minerais era efectuada essencialmente recorrendo ao microscópio de luz polarizada que permitia a respectiva caracterização morfológica (Figura 6). No entanto apenas com esta técnica não era possível obter informação acerca do arranjo estrutural dos átomos no interior dos cristais. A descoberta da difracção de raios-X por pós em 1916-1917 levou a um aumento significativo do número de estruturas de minerais determinadas.

Quando W.H. Bragg e R.E. Gibbs iniciaram o estudo do quartzo, já várias estruturas mais simples haviam sido elucidadas. A descoberta das estruturas do quartzo- $\alpha$ e $\beta$ em 1925 marcou o início de um extenso trabalho sobre silicatos, com a maioria das contribuições nesta área provenientes de discípulos de Bragg [24]. Com o aumento do número de estruturas cristalinas determinadas, tornou-se 
necessário racionalizar princípios teóricos que permitissem a interpretação dos dados obtidos. Em 1926, Victor Goldschmidt postulou algumas regras sobre a substituição de átomos em estruturas cristalinas [25], que serviram de inspiração a Linus Pauling, que veio a formular um conjunto de regras que foram pela primeira vez colocadas em prática no estudo de zeólitos [26]. Em 1930, e com toda a informação disponível até aquela altura, W.L. Bragg estabelece então a primeira classificação compreensiva dos silicatos [27]. Os estudos dos mineralogistas passaram também a focar-se nas imperfeições e defeitos dos cristais, uma vez que estas microestruturas podem estar relacionadas com a génese dos cristais de minerais, fornecendo assim informação sobre o ambiente em que esta ocorreu.

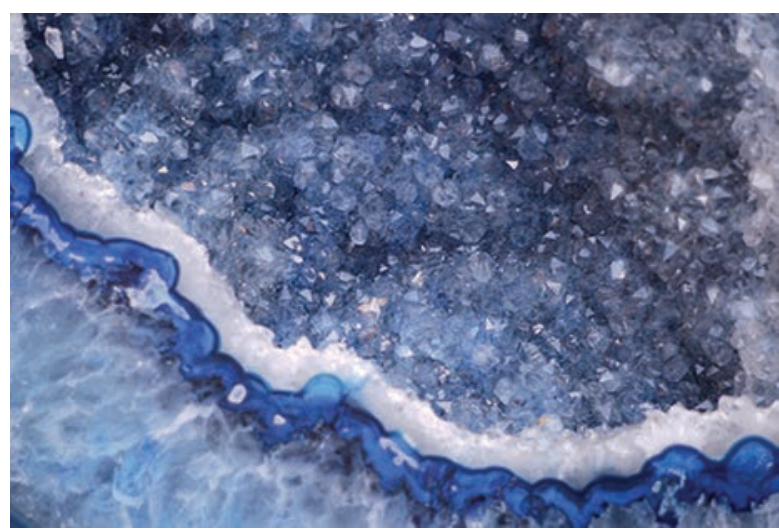

Figura 6 - Cristais de quartzo (cortesia de Patrícia Blázquez)

\section{CONFIGURAÇ̃̃o ABSOLUTA dO ÁCIDO TARTÁRICO}

No final do século XIX os químicos começaram a preocupar-se em representar a organização espacial de moléculas com centros quirais e a distinguir estereoisómeros. Uma das observações da altura é que pares de moléculas com ligações atómicas idênticas podiam rodar o plano da luz polarizada em direcções opostas, designando-se por enantiómeros. A década de 1880 fora marcada pela extensa contribuição de Emil Fischer na síntese e conhecimento dos hidratos de carbono, o que lhe valeu o Prémio Nobel da Química em 1902. E. Fischer havia sugerido um modo de representar estereoisómeros, desenhando-os como uma projecção bidimensional - projecção de Fischer. Este modo de representação foi usado para representar a estereoquímica de açúcares, aminoácidos e outras moléculas orgânicas. De uma forma totalmente aleatória, Fischer classificou o enantiómero D da glucose como o isómero + (que desvia o plano de luz polarizada no sentido horário) e o isómero L como - (que promove um desvio no sentido anti-horário). Martin Rosanoff prosseguiu com esta classificação tendo analisado outras moléculas quirais como o gliceraldeído [28].

Contudo, apenas em 1951, foi possível confirmar a classificação de Fischer graças aos trabalhos de cristalografia por raios-X realizados por Bijvoet e colaboradores. Nas suas experiências, Bijvoet usou uma fonte de radiação de zircónio e um sal de sódio e rubídio da forma natural (+) do ácido tartárico. A possibilidade de excitar apenas os átomos de rubídio graças ao comprimento de onda da radiação es- colhida (método da dispersão anómala), permitiu determinar a configuração absoluta de todos os átomos do cristal [29]. Ficava assim confirmado que a forma natural (+) do ácido tartárico correspondia efectivamente à configuração L proposta previamente por Fischer.

A dispersão anómala estabeleceu-se, assim, como uma ferramenta capaz de confirmar a estereoquímica absoluta de novas moléculas, corroborando simultaneamente os modelos quirais anteriormente propostos na literatura.

\section{A estrutura do ferroceno}

Em 1951, sem o terem como objectivo, Peter Pauson e Tom Kealy sintetizaram inadvertidamente um composto altamente estável, de fórmula $\mathrm{C}_{10} \mathrm{H}_{10} \mathrm{Fe}$, [30] quando tentavam produzir o fulvaleno, um hidrocarboneto pouco usual constituído por 2 anéis de ciclopentadieno unidos por uma ligação $\mathrm{C}=\mathrm{C}$. A estrutura daquele composto inesperado era difícil de atribuir, nomeadamente no respeitante à ligação dos anéis de cinco membros ao átomo de ferro. Os autores propuseram então uma estrutura linear em que os dois anéis se ligavam ao átomo de Fe por ligações simples, o que fora também proposto, quase em simultâneo, por Miller, Tebboth e Tremaine [31].

Pouco depois, a proposta do carácter linear da estrutura foi posta em causa por Robert Woodward e Geoffrey Wilkinson que, baseando-se em informação indirecta, em particular de espectroscopia de infra-vermelhos, avançaram com um modelo em sandwich com o átomo de Fe entre os dois anéis [32]. Ainda em 1952, a estrutura em sandwich foi confirmada por Ernst Fischer e Wolfgang Pfab usando cristalografia por raios-X. Na estrutura cristalina, o átomo de Fe ocupa o centro dum anti-prisma pentagonal definido pelos 2 anéis paralelos de ciclopentadienilo [33] (Figura 7).

O composto foi designado por ferroceno e veio refundar a química organometálica levando ao posterior aparecimento de outros compostos em sandwich com outros metais e diferentes sistemas aromáticos. A importância desta descoberta levou à atribuição do Prémio Nobel da Química em 1973 a E.O. Fischer e G. Wilkinson.

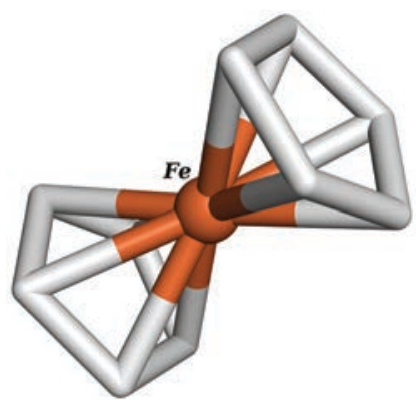

Figura 7 - Estrutura do ferroceno

\section{ESTRUTURA SECUNDÁRIA DE PROTEÍNAS E A ESTRUTURA DO DNA}

Até meados do século XX, a estrutura das proteínas continuava envolta em mistério apesar de, em 1936, Alfred Mirsky e Linus Pauling terem destacado a enorme impor- 
tância das ligações por pontes de hidrogénio na definição da estrutura das proteínas. Nos 15 anos seguintes, Pauling e colaboradores focaram-se no estudo sistemático das ligações de hidrogénio em cadeias polipeptídicas, inspirados em trabalhos anteriores de William Astbury e recorrendo a estruturas cristalinas de aminoácidos e de pequenos péptidos. Em 1951, Pauling e Corey reportaram pela primeira vez a existência de elementos estruturais em proteínas: hélices- $\alpha$ e folhas- $\beta$ [34,35].

Os trabalhos de Linus Pauling tiveram um enorme impacto na química estrutural, e em 1954 este recebeu o Prémio Nobel da Química pela sua “investigação acerca da natureza da ligação química e na elucidação da estrutura de substâncias complexas”.

Em relação ao DNA, identificado como uma macromolécula nos anos 30, existiram várias hipóteses para a sua estrutura (nomeadamente o modelo de hélice tripla de Pauling). Em 1950, James Watson e Francis Crick, com o auxílio de Jerry Donohue, tentavam interpretar os resultados de Chargaff que previa a existência dos pares de bases A-T e G-C. Em paralelo, Maurice Wilkins seguido de Rosalind Franklin haviam iniciado a análise por cristalografia de fibras de DNA. Watson e Crick acederam aos padrões de difracção de fibras obtidos por Rosalind Franklin sem o seu consentimento (como é do conhecimento geral), cuja informação, quando combinada com os dados que já possuíam, lhes permitiu progredir e avançar com o famoso modelo da dupla hélice - “demasiado belo para não ser verdade” [36]. Em 1962, Crick, Watson e Wilkins receberam o Prémio Nobel da Fisiologia ou Medicina pela descoberta pioneira da estrutura do DNA, que teve um enorme impacto no desenvolvimento da Biologia Molecular.

\section{AS PRIMEIRAS ESTRUTURAS DE PROTEÍNAS}

Foi em 1937 que Max Perutz e os seus colaboradores foram confrontados com o "problema da fase” em cristalografia. Tinham conseguido obter cristais de hemoglobina que difractavam os raios-X e obtido um padrão de difracção mas, para resolver a estrutura tridimensional desta proteína que transporta o oxigénio nos glóbulos vermelhos, tinham que conhecer os ângulos de fases das ondas difractadas. Foi numa publicação em 1954 que David Green, Vernon Ingram e Max Perutz descreveram como tinham resolvido o "problema da fase" [37]. Este grupo de cientistas usou pela primeira vez o método de substituição isomórfica, que consiste em introduzir átomos “pesados” (neste caso, mercúrio) no cristal de hemoglobina, utilizando para o efeito compostos de mercúrio que iriam formar complexos com os átomos de enxofre livres na proteína [38]. Nesse artigo os autores mostravam como este método podia ser utilizado para a determinação directa de uma estrutura proteica. Foi apenas seis anos mais tarde, depois de muito trabalho a analisar milhares de reflexões e a construir quatro cadeias polipeptídicas que a estrutura da hemoglobina foi publicada a 5,5 Å de resolução [38]. Curiosamente, verificou-se que cada uma destas cadeias era semelhante à estrutura preliminar da proteína que liga o oxigénio nos músculos, a mioglobina, reportada por John Kendrew em 1958 a $6 \AA$ de resolução. Neste caso, o "problema da fase” fora também resolvido a partir de derivados isomórficos contendo mercúrio e ouro. Em 1960, John Kendrew e os seus colaboradores determinaram finalmente a estrutura da mioglobina de cachalote, a uma resolução de 2,0 $\AA$ [39] (Figura 8). Neste caso, como a estrutura apresentava uma alta-resolução já foi possível visualizar interacções atómicas, incluindo as hélices $\alpha$ direitas (right handed) e a posição do grupo hemo na estrutura. Os avanços derivados deste trabalho tiveram um enorme impacto e reconhecimento na comunidade científica, e em 1962 o Prémio Nobel da Química foi atribuído a Max Perutz e John Kendrew.
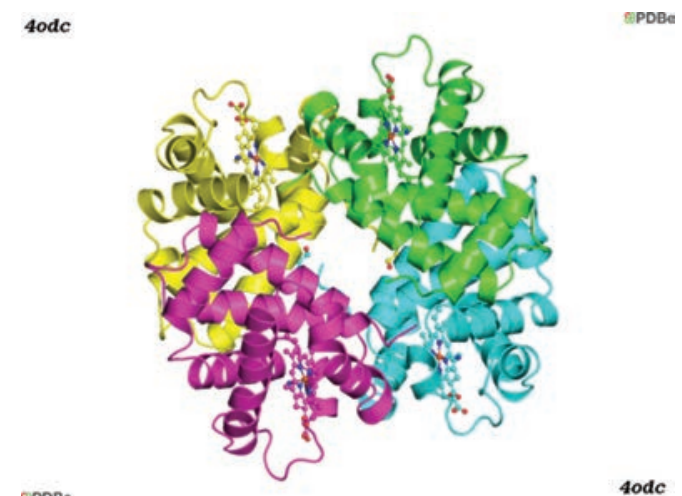

Figura 8 - Estrutura tridimensional da hemoglobina (imagem preparada com o programa Chimera e coordenadas PDB 4odc)

\section{DifracÇÃo dE NEUTRÕES}

Quando a radiação de neutrões foi descoberta por volta dos anos 1930, já a difracção de raios-X era usada para revelar a estrutura interna dos cristais. Pensou-se então que a radiação de neutrões poderia ser utilizada para o mesmo fim, pois os neutrões livres teriam um comprimento de onda comparável às distâncias interatómicas num cristal. No entanto, à data, as fontes de neutrões eram muito fracas para constituírem uma ferramenta útil, e foi durante a Segunda Guerra Mundial que o maior avanço ocorreu, quando se concluíram os primeiros reactores nucleares. Após a guerra, vários cientistas procuraram fazer o melhor uso possível das instalações recentemente disponíveis: entre estes destacam-se Ernst Wollan e Clifford Shull que desenvolveram os princípios de difracção de neutrões. Em 1949, na Physical Review, é publicado por Shull e James Smart, um artigo de uma página, reportando a ocorrência de apenas alguns picos de dispersão de neutrões para o óxido de manganês [40]. Este artigo não fez mais do que confirmar uma hipótese fundamental do magnetismo colocada por Louis Néel, em 1921, que sugeria que alguns materiais podem ser magneticamente ordenados, sem serem magnéticos. Nestes anti-ferromagnetos, os momentos magnéticos elementares, ou spins, teriam orientações alternadas e cancelavam-se mutuamente. Os neutrões possuem um spin, funcionando eles próprios como pequenos magnetos. O que Smart sugeriu foi que a difracção de neutrões poderia permitir detectar directamente o antiferromagnetismo. Smart estava certo e assim se iniciou uma nova área, a da cristalografia magnética, com uma importância única para a difracção de neutrões. Na década de 1940, as fontes de neutrões disponíveis 
limitavam-se aos reactores nucleares o que atrasava o seu progresso. No entanto, com a introdução de novos projectos de colaboração, onde a comunidade científica poderia ter acesso a grandes infraestruturas, esta limitação deixou de existir. Hoje em dia, existem no mundo várias infraestruturas com reactores nucleares, e a difracção de neutrões tornou-se uma ferramenta essencial em áreas tão diversas como a optimização de novos materiais para armazenamento de energia [41] ou na determinação da estrutura de vírus e de proteínas. Em ciência fundamental, a dispersão de neutrões continua a ser de enorme importância, como uma sonda de formas pouco comuns de magnetismo.

\section{As GRANDES FONTES DE RADIAÇÃO}

O aparecimento de laboratórios para a produção e utilização de radiação de sincrotrão (vulgarmente designados por Sincrotrões) foi determinante para muitos avanços científicos, muito particularmente para a análise estrutural por Cristalografia. Um Sincrotrão produz radiação electromagnética a partir da aceleração radial de partículas carregadas, com recurso a grandes magnetos. O custo de construção é muito elevado e normalmente suportado pelas entidades financiadoras de países desenvolvidos. A utilização da infraestrutura é disponibilizada a cientistas de várias áreas, sob a forma de diferentes linhas especializadas (beamlines). O primeiro sincrotrão de electrões foi projectado em 1945 por Edwin McMillan [42,43], embora o princípio do funcionamento tenha sido publicado, num jornal soviético em 1944, por Vladimir Veksler [44]. Dois dos mais antigos grandes Sincrotrões, já desactivados, foram o Bevatron, construído no Lawrence Berkeley Laboratory (Califórnia, EUA), e o Cosmotron, construído no Brookhaven National Laboratory (Nova Iorque, EUA). Exemplos de fontes de radiação de sincrotrão modernas são o European Synchrotron Radiation Facility (ESRF) (Figura 9) e o Soleil, ambos em França, o Diamond Light Source, no Reino Unido, o Swiss Light Source na Suíça, o Advanced Photon Source (APS) em Chicago, nos EUA, e o SPring-8 no Japão. Os mais modernos aceleradores de partículas, como o LHC (Large Hadron Collider) no CERN construído em 2008 na Suíça e com 27 km de diâmetro, baseiam-se no funcionamento dos sincrotrões. Portugal é membro associado do ESRF desde 1998 e membro do CERN desde 1986. Novas infraestruturas com potencial impacto para a biologia estrutural estão em desen-

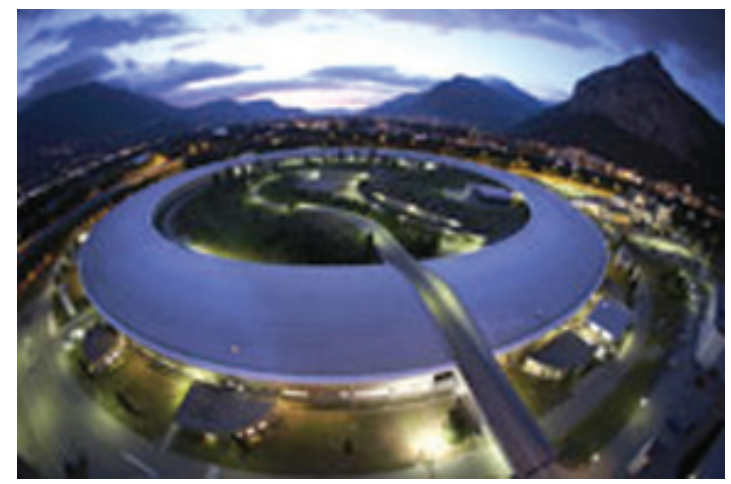

Figura 9 - O edifício das beamlines e do anel de armazenamento da infrastrutura de radiação de sincrotrão ESRF (imagem cortesia de P.Ginter/ ESRF) volvimento como o XFEL (do inglês $X$-ray free-electron laser), que permite determinar diferentes tipos de estruturas, tal como células e vírus, e tornou mais real a possibilidade de obter filmes de processos moleculares. Adivinha-se um futuro muito promissor para a Ciência dos XFEL.

\section{Bases de dados CRISTALOgRÁFICOS}

O Protein Data Bank (PDB) foi criado em 1971, na sequência de uma conferência realizada em Cold Spring Harbor, intitulada Structure and Function of Proteins at the Three Dimensional Level. Nessa conferência os cristalógrafos de macromoléculas debateram a preocupação acerca da criação de um repositório para dados cristalográficos de proteínas, que fosse acessível a todos. Pouco tempo depois foi publicado na Nature New Biology a criação oficial do repositório de dados cristalográficos de proteínas (PDB), coordenado pelo Brookhaven National Laboratory (EUA) e pelo Centro de Dados Cristalográficos (moléculas pequenas) em Cambridge (Reino Unido) [45]. A criação deste repositório constitui um marco histórico, pois naquele tempo a partilha da informação estrutural entre a comunidade científica era muito difícil e o software disponível ainda muito escasso. Com a criação do PDB, surgia a necessidade de criar programas interactivos que permitissem visualizar as estruturas 3D, assim como programas que permitissem armazenar e procurar estruturas no PDB [46-48]. Seguindo a tradição que existia na comunidade de cristalógrafos em partilhar software é em 1979 criado o Collaborative Computational Project Number 4 (CCP4), por um grupo de cientistas no Reino Unido. Este projeto teve como objectivo desenvolver software, e outro tipo de ferramentas computacionais, para processar e analisar dados cristalográficos. Hoje em dia o CCP4 reúne um conjunto de programas que é usado por toda a comunidade de cristalógrafos [49].

Durante os anos oitenta, para além de se ter verificado um grande desenvolvimento das metodologias usadas para resolver estruturas 3D, houve também um enorme avanço nas tecnologias computacionais, o que levou a um aumento exponencial do número de estruturas depositadas no PDB que em 2014 ultrapassou as 100.000 (Figura 10). A maioria das revistas científicas exige a deposição dos modelos estruturais das proteínas, e dos dados experimentais asso-

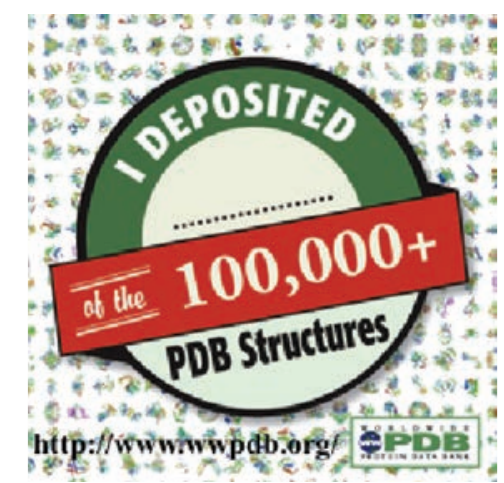

Figura 10 - Selo comemorativo da deposição de 100000 estruturas no PDB, emitido durante a comemoração do Ano Internacional da Cristalografia 2014 
ciados como pré-requisito para a publicação do manuscrito. O PDB é distribuído a partir de vários locais, em três continentes: o Research Collaboratory of Structural Bioinformatics (RCSB PDB) nos EUA, o Protein Data Bank na Europa (PDBe) do EMBL-EBI's e o PDB Japan (PDBj). Tendo começado apenas com sete estruturas nos anos 1970, o PDB tem hoje mais de 106.000 estruturas depositadas, das quais mais de 87.000 determinadas por Cristalografia por Raios-X, com acesso sem restrições a toda a comunidade científica.

\section{A dESCOBERTA DOS QUASICRISTAIS}

Em 1984 Dan Shechtman pôs a comunidade de cristalógrafos em sobressalto, quando publicou um trabalho que questionava a definição, até à data perfeitamente estabelecida, de que um cristal era um arranjo periódico de células unitárias. Nesse trabalho [50], Shechtman apresentava as suas observações experimentais acerca de uma liga de alumínio que tinha sido rapidamente arrefecida para evitar a cristalização do material. Usando difracção de electrões verificou que uma região muito pequena do sólido produzia um padrão de difracção muito bem definido, e que sugeria a presença de simetria rotacional de grau 10 e simetria translacional não-periódica (Figura 11). Num cristal convencional, apenas é possível encontrar simetria de grau 2, 3, 4 e 6, com células unitárias que preenchem completamente o espaço disponível e num arranjo periódico. Assim sendo, esta liga de alumínio não poderia ser um cristal, mas difractava como tal. No final de 1984, e inspirados nos padrões de mosaicos de Penrose, os físicos Dov Levine e Paul Steinhardt [51] (e mais tarde o cristalógrafo Alan Mackay [52]) sugeriram uma explicação: teoricamente, a aperiodicidade seria possível em três dimensões, e um padrão de difracção simulado de um mosaico de Penrose exibiria simetria de grau 5. Designaram estas estruturas por quasicristais. A evidência experimental em materiais diversos (incluindo minerais naturais) rapidamente conquistou adeptos da teoria da quasi-periodicidade. Em 1992, a União Internacional de Cristalografia alterou a sua definição de um cristal para "qualquer sólido que produza um padrão de difracção essencialmente discreto", o que constituiu o reconhecimento formal da existência de quasicristais. A confiança de Shechtman nas suas observações, questionando o que outros

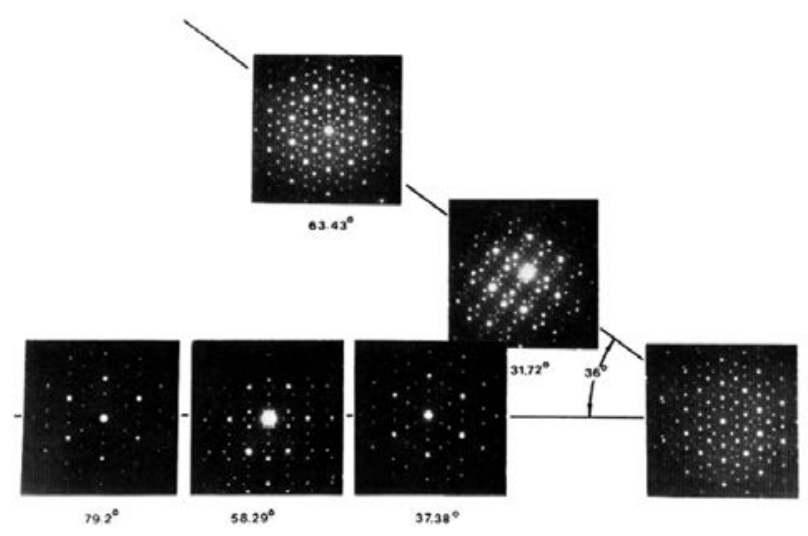

Figura 11 - Imagens originais de difracção por electrões tiradas por Dan Shechtman. As relações angulares entre as várias zonas examinadas por Shechtman revelam que a amostra possui simetria icosaédrica (imagem cortesia de http://www.nobelprize.org) consideravam estabelecido, fê-lo merecedor do Prémio Nobel da Química em 2011.

\section{Cristais artificials porosos (Metal Organic Fra- MEWORKS, MOFS)}

Durante grande parte do século XX, a síntese de sólidos cristalinos resultava muitas vezes de uma feliz combinação de eventos. A conjugação de conhecimentos de química e cristalografia conduziu a um aumento do número de compostos cristalinos especialmente concebidos com estruturas e propriedades pré-determinadas. Na vanguarda da síntese destes materiais estiveram os cristais porosos, estruturas que contêm nanoporos, nos quais se podem ligar moléculas e/ou iões com diferentes tamanhos e formas. Estes cristais sintéticos encontram análogos na natureza, sob a forma de aluminossilicatos (zeólitos). Os primeiros relatos da síntese de zeólitos em laboratório datam da década de 1860, mas foi o trabalho de Richard Barrer na década de 1940 que iniciou uma era de grande produção de zeólitos sintéticos. Em 1948, Barrer reportou a síntese de um zeólito sintético análogo à mordenite, que foi caracterizado por difracção de raios-X por pós [53]. Mais tarde, graças ao trabalho de Robert Milton e Donald Breck foi possível a comercialização dos primeiros zeólitos sintéticos. Os zeólitos são materiais inteiramente inorgânicos cuja constituição final é difícil de controlar devido à sua composição química. Assim, os cientistas passaram a utilizar uma combinação de componentes orgânicos e inorgânicos para a síntese de cristais porosos, o que levou a um aumento do interesse nos cristais designados por metal-organic frameworks (MOFs), a partir dos finais do século XX [54-56] (Figura 12). Até aos dias de hoje, dezenas de milhares de estruturas MOF com diferentes propriedades foram sintetizadas, tendo aplicabilidade em processos de catálise, na distribuição de fármacos, no armazenamento de hidrogénio, ou na adsorção reversível de dióxido de carbono.

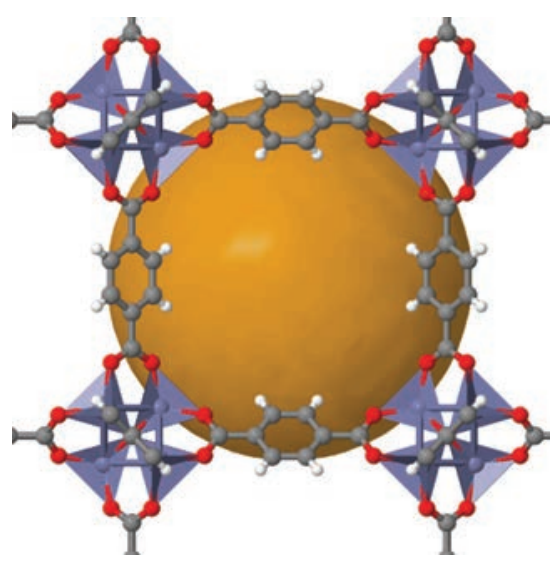

Figura 12 - MOF-5 e respectiva célula unitária que forma uma cavidade representada pela esfera a laranja

\section{ESTRUTURAS DE VÍRUS E A SIMETRIA MOLECULAR}

Um dos marcos que mais comprovou a importância da cristalografia na investigação biomédica foi a caracterização estrutural de partículas virais, com toda a informação que veio a fornecer acerca da interacção vírus-célula hos- 
pedeira, assim como da relevância do arranjo simétrico de módulos proteicos para os mecanismos de entrada de um vírus numa célula. As primeiras estruturas cristalinas de vírus de RNA de plantas revelaram a simetria inerente das cápsides virais. O vírus do tomateiro (TBSV, tomato bushy stunt virus) é constituído por uma cadeia simples de RNA encapsulada numa cápside icosaédrica com um revestimento de 180 subunidades proteicas. Em 1978, Harrison et al. revelaram a primeira imagem de alta resolução de como as proteínas idênticas do revestimento se organizam em combinações de pentâmeros e hexâmeros para produzirem um vírus esférico [57] (Figura 13). Dois anos mais tarde, Abad-Zapatero et al. resolveram a estrutura cristalina da cápside do vírus do mosaico do feijão (SBMV, southern bean mosaic virus), revelando o mesmo arranjo das subunidades proteicas [58]. Em 1981, Wilson et al. revelaram a primeira imagem de um antigénio de superfície de um vírus patogénico [59]. Além de um invólucro membranar lipídico (adquirido quando emerge da superfície da célula hospedeira), o vírus da gripe humana possui duas glicoproteínas, a hemaglutinina e a neuraminidase. A hemaglutinina organiza-se em homotrímeros que se ligam aos receptores de superfície da célula hospedeira, participando activamente na fusão membranar entre o vírus e a célula.
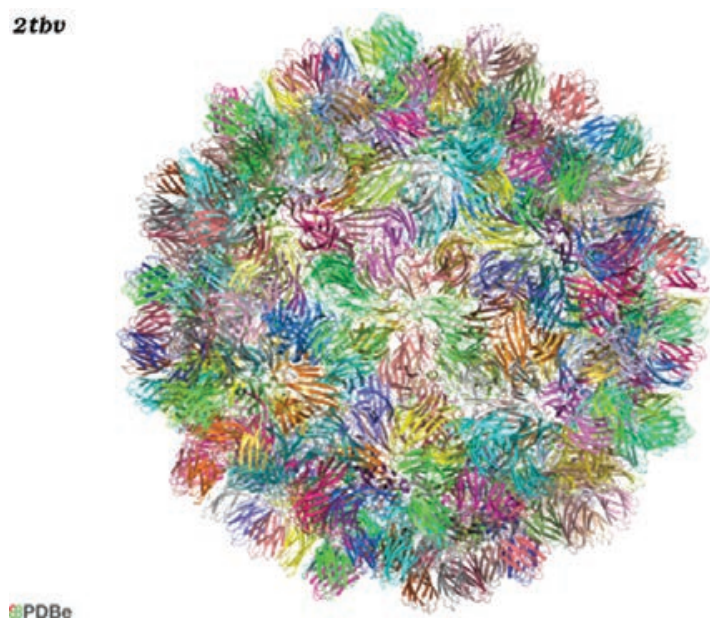

MPDBe

Figura 13 - Representação do revestimento proteico (180 cópias) da cápside do vírus do tomateiro TBSV (tomato bushy stunt virus) (figura obtida em http://www.ebi.ac.uk/pdbe-srv/view/entry/2tbv)

\section{Os GRANDES DESAFIOS DA BIOLOGIA ESTRUTURAL MO- DERNA}

Com menos de 600 estruturas únicas depositadas no PDB, as proteínas integradas nas membranas biológicas (20-30\% do genoma humano) são consideradas o grande desafio actual da resolução de estruturas por cristalografia, sendo que a grande dificuldade reside na obtenção de cristais destas proteínas. Em 1985, Michel et al. revelaram a primeira estrutura de alta resolução de uma proteína integral de membrana, o Centro Reaccional Fotossintético, observando a interacção da superfície hidrofóbica das proteínas com os lípidos da bicamada fosfolipídica [60] (Figura 14). Mais tarde, Schulz et al. revelaram a primeira estrutura de uma porina, explicando como ocorre a difusão passiva através das membranas biológicas [61]. Também importante, foi a

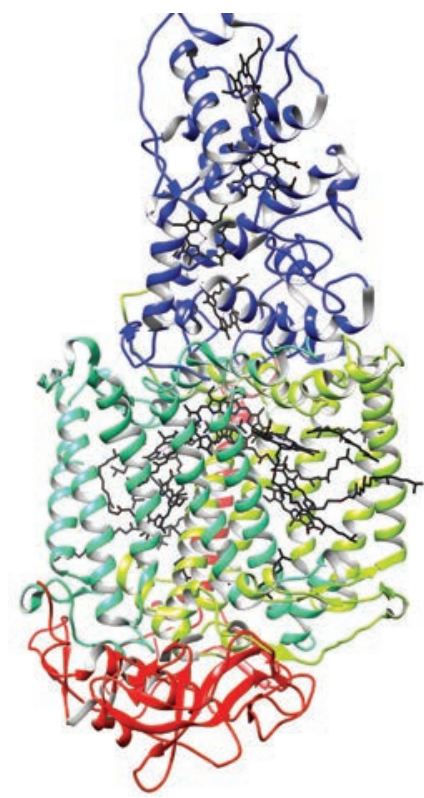

Figura 14 - Centro Reaccional Fotossintético de Rhodopseudomonas viridis (imagem preparada com o programa Chimera e coordenadas PDB 1prc)

resolução da estrutura da $\mathrm{F}_{1}$-ATPase [62], uma verdadeira máquina onde o fluxo de protões induz a rotação do domínio $\mathrm{F}_{1}$ e a consequente produção de adenosina trifosfato. $\mathrm{O}$ desenvolvimento da técnica de cristalização em fases cúbicas lipídicas (LCP, lipidic cubic phase) foi crucial para a obtenção de estruturas importantes como a bacteriorodopsina [63] e os receptores associados à proteína G (GPCRs, G protein-coupled receptors) [64].

Outro grande desafio que merece ser referido é a caracterização estrutural de complexos entre proteínas e ácidos nucleicos, com todo o potencial de informação que pode providenciar sobre importantes fenómenos como a tradução e a transcrição genéticas. Em 1979, Alex Rich determinou a primeira estrutura cristalina da forma Z do DNA [65], mas antes, em 1973, havia publicado a primeira estrutura de um RNA de transferência [66]. A resolução da estrutura do primeiro complexo proteína-ácido nucleico deu-se em 1984 com a estrutura do nucleossoma com $206 \mathrm{kDa}$ [67]. A dimensão megaDalton foi atingida em 2001 com a estrutura completa do ribossoma $70 \mathrm{~S}$ de Thermus thermophilus, incluindo tRNAs nos locais A, P e E e um mRNA, elucidando o mecanismo de tradução genética [68]. Para a compreensão do fenómeno da transcrição, foram cruciais as estruturas da Polimerase II do RNA de Saccharomyces cerevisiae isolada [69], e também em complexo com um fragmento de DNA [70].

A enorme importância destes resultados para o avanço do conhecimento é reflectida no número de Prémios Nobel, todos eles envolvendo a cristalografia de raios-X: Nobel da Química 1988 a H. Michel, J. Deisenhofer e R. Huber (Centro Reaccional Fotossintético); Nobel da Química 1997 a P. Boyer e J. Walker e J. Skou (Síntese de ATP e ATPases); Nobel da Química 2009 a V. Ramakrishnan, T. Steitz e A. Yonath (Ribossoma); Nobel da Química 2012 a R. Lefkowitz e B. Kobilka (GPCRs). 


\section{Agradecimentos}

Agradecemos ao Hugo Correia a assistência na preparação das Figuras 5 e 12 e ao João Pedro Veiga (CENIMAT, FCT-UNL) e Carlos C. Romão (ITQB-UNL) a revisão de partes deste artigo. À FCT-MEC o financiamento dos projectos: RECI/BBB-BEP/0124/2012; PTDC/QUI-BIQ /117799/2010; PTDC/BIA-PRO/118377/2010 e a bolsa SFRH/BD/77894/2011 a MFAS.

\section{REFERÊNCIAS}

[1] “Milestones in Crystallography" Nature (2014) doi: 10.1038/nature13348

[2] R.J. Haüy, “Essai d'une Théorie sur la Structure des Crystaux”, Gogué et Née de La Rochelle, 1784

[3] J.F.C. Hessel, "Kristallometrie oder Kristallonomie und Kristallographie”, E. B. Schwickert, 1830

[4] A. Bravais, J. l'Ecole Polytechnique 19 (1850) 1

[5] A. Schönflies, "Kristallsysteme und Kristallstruktur”, B. G. Teubner, 1891

[6] W.C. Röntgen, Sitzungsber. Der Würzburger Physik-Medic. Gesellsch. 137 (1895) 132-141

[7] W. Wien, Nachrichten Kgl. Gesell. Wiss. GÖttingen 5 (1907) 598-601

[8] J. Stark, Nature 77 (1908) 320

[9] W. Friedrich, P. Knipping, M. Laue, Sitzungsberichte der Kgl. Bayer. Akad.der Wiss. (1912) 303-322

[10] M. von Laue, Sitzungsberichte der Kgl. Bayer. Akad. Der Wiss. (1912) 363-373

[11] W.L. Bragg, Nature 90 (1912) 410

[12] W.L. Bragg, Proc. Cambridge Phil. Soc. 17 (1913) 43-57

[13] W.H. Bragg, W.L. Bragg, Nature 94 (1914) 199-200

[14] W.L. Bragg, Proc. Royal. Soc. Lond. A 89 (1913) 248-77

[15] W.H. Bragg, Nature 90 (1912) 219; W.H. Bragg, Nature 90 (1912) 360-361

[16] W.H. Bragg, W.L. Bragg, Nature 91 (1913) 557

[17] A.H. Compton, Nature 95 (1915) 343-344

[18] P.P. Ewald, Nature 195 (1962) 320-325

[19] H.W. Gonell, H. Mark, Z. Phys. Chem.107 (1923) 181-218

[20] R.G. Dickinson, A.L. Raymond, J. Am. Chem. Soc. 45 (1923) 22-29

[21] K. Lonsdale, Nature 122 (1928) 810

[22] K. Lonsdale, Proc. R. Soc. A 123 (1929) 494-515

[23] K. Lonsdale, Trans. Faraday Soc. 25 (1929) 352-366

[24] W.H. Bragg, R.E. Gibbs, Proc. R. Soc. Lond. A 109 (1925) 405-426

[25] V.M. Goldschmidt, "Geochemische Verteilungsgesetze, VII: Die Gesetze der Krystallochemie”, Skrifter Norsk. Vid. Akademie, Oslo, Mat. Nat. Kl., 1926

[26] L. Pauling, J. Am. Chem. Soc. 51 (1929) 1010-1026

[27] W.L. Bragg, Z. Kistallogr. 74 (1930) 237-305
[28] M.A. Rosanoff, J. Am. Chem. Soc. 28 (1906) 114-121

[29] J.M. Bijvoet, A.F. Peerdeman, A.J. van Bommel, Nature 168 (1951) 271-272

[30] T.J. Kealy, P.L. Pauson, Nature 168 (1951) 1039-1040

[31] S.A. Miller, J.A. Tebboth, J.F. Tremaine, J. Chem. Soc (1952) 632-635

[32] G. Wilkinson, M. Rosenblum, M.C. Whiting, R.B. Woodward, J. Am. Chem Soc. 74 (1952) 2125-2126

[33] E.O. Fischer, W.Z. Pfab, Naturforsch. B 7 (1952) 377-379

[34] L. Pauling, R.B. Corey, H.R. Branson, Proc. Natl Acad. Sci. USA 37 (1951) 205-211

[35] R.B. Corey, L. Pauling, Proc. Natl Acad. Sci. USA 37 (1951) 251-256

[36] J.D. Watson, F.H.C. Crick, Nature 171 (1953) 737-738

[37] D.W. Green, V.M. Ingram, M.F. Perutz, Proc. Royal Soc. Lond. A 225 (1954) 287-307

[38] M.F. Perutz, M.G. Rossmann, A.F. Cullis, H. Muirhead, G. Will, A.C.T. North, Nature 185 (1960) 416-422

[39] J.C. Kendrew, R.E. Dickerson, B.E. Strandberg, R.G. Hart, D.R. Davies, D.C. Phillips, V.C. Shore, Nature 185 (1960) 422-427

[40] C.G. Shull, J.S. Smart, Phys. Rev. 76 (1949) 1256

[41] S. Mühlbauer, B. Binz, F. Jonietz, C. Pfleiderer, A. Rosch, A. Neubauer, R. Georgii, P. Böni, Science 323 (2009) 915$-919$

[42] E.J. Wilson, “Fifty Years of Synchrotrons”, EPAC 96: Proceedings of the Fifth European Particle Accelerator Conference, Barcelona, 1996

[43] J.D. Jackson, W.K.H. Panofsky, "EDWIN MATTISON MCMILLAN: A Biographical Memoir”, National Academy of Sciences, Washington D.C., 1996

[44] V.I. Veksler, Comptes Rendus (Doklady) de l'Academie Sciences de l'URSS 43(8) (1944) 329-331

[45] Protein Data Bank, Nature New Biol. 233 (1971) 223

[46] E.F. Jr Meyer, Nature 232 (1971) 255-257

[47] E.F. Jr Meyer, Biopolymers 13 (1974) 419-422

[48] E.F. Jr Meyer, C.N Morimoto, J. Villarreal, H.M. Berman, H.L Carrell, R.K. Stodola, T.F. Koetzle, L.C. Andrews, F.C. Bernstein, H.J. Bernstein, J. Villarreal, Fed. Proc. 33 (1974) 2402-2405

[49] Collaborative Computational Project, Acta crystallogr. D 50 (1994) 760-763

[50] D. Shechtman, I. Blech, D. Gratias, J.W. Cahn, Phys. Rev. Lett. 53 (1984) 1951-1953

[51] D. Levine, P.J. Steinhardt, Phys. Rev. Lett. 53 (1984) 2477$-2480$

[52] A.L. Mackay, Physica 114A (1982) 609-613

[53] M. Barrer, J. Chem. Soc. (1948) 2158-2163

[54] B.F. Hoskins, R. Robson, J. Am. Chem. Soc. 111 (1989) 5962-5964

[55] O.M. Yaghi, H. Li, J. Am. Chem. Soc. 117 (1995) 10401$-10402$ 
[56] H. Li, M. Eddaoudi, M. O’Keeffe, O.M. Yaghi, Nature 402 (1999) 276-279

[57] S.C. Harrison, A.J. Olson, C.E. Schutt, F.K. Winkler, G. Bricogne, Nature 276 (1978) 368-373

[58] C. Abad-Zapatero, S. S. Abdel-Meguid, J. E. Johnson, A. G. W. Leslie, I. Rayment, M. G. Rossmann, D. Suck, T. Tsukihara, Nature 286 (1980) 33-39

[59] I.A. Wilson, J.J. Skehel, D.C. Wiley, D. C. Nature 289 (1981) 366-373

[60] J. Deisenhofer, O. Epp, K. Miki, R. Huber, H. Michel, Nature 318 (1985) 618-624

[61] M.S. Weiss, U. Abele, J. Weckesser, W. Welte, E. Schiltz, G.E. Schulz, Science 254 (1991) 1627-1630

[62] J.P. Abrahams, A.G. Leslie, R. Lutter, J.E. Walker, Nature 370 (1994) 621-628

[63] E. Pebay-Peyroula, G. Rummel, J.P. Rosenbusch, E.M. Landau, Science 277 (1997) 1676-1681
[64] S.G.F. Rasmussen, H-J. Choi, D.M. Rosenbaum, T.S. Kobilka, F.S. Thian, P.C. Edwards, M. Burghammer, V.R.P. Ratnala, R. Sanishvili, R.F. Fischetti, G.F.X. Schertler, W.I. Weis, B.K. Kobilka, Nature 450 (2007) 383-387

[65] A.H.J. Wang, G.J. Quigley, F.J. Kolpak, J.L. Crawford, J.H. Van Boom, G. Van Der Marel, A. Rich, Nature 282 (1979) 680-686

[66] S.H. Kim, G.J. Quigley, F.L. Suddath, A. McPherson, D. Sneden, J. J. Kim, J. Weinzierl, A. Rich, Science 179 (1973) 285-288

[67] T.J. Richmond, J.T. Finch, B. Rushton, D. Rhodes, A. Klug, Nature 311 (1984) 532-537

[68] M.M. Yusupov, G.Z. Yusupova, A. Baucom, K. Lieberman, T.N. Earnest, Science 292 (2001) 883-896

[69] P. Cramer, D.A. Bushnell, R.D. Kornberg, Science 292 (2001) 1863-1876

[70] A.L. Gnatt, P. Cramer, J. Fu, D.A. Bushnell, R.D. Kornberg, Science 292 (2001) 1876-1882

\section{Actualidades Científicas}

\section{INTERCONVERSÃO [2]ROTAXANO - [2]CATENANO INDUZIDA PELA LUZ}

Investigadores europeus descreveram um sistema molecular entrelaçado mecanicamente que pode alternar, de modo reversível, entre um rotaxano e catenano.

Os rotaxanos, assim como os catenanos, são grupos de moléculas importantes na área da electrónica molecular. Os rotaxanos são macromoléculas compostas por um anel macrocíclico em torno de um eixo molecular com uma forma que faz lembrar um haltere. Os catenanos, por sua vez, são formados por dois ou mais macrociclos interligados entre si. A síntese de um rotaxano é relativamente simples, ao contrário da de um catenano. A síntese de um rotaxano que se transforme num catenano é também bastante difícil.

Recentemente, um equipa de investigadores liderada por Alberto Credi, da Universidade de Bolonha, mostrou que a luz pode ser usada como estímulo para a interconversão reversível entre um [2]rotaxano e um [2]catenano. Este processo passa por uma fotociclomerização $[4 \pi+4 \pi]$ totalmente reversível dos grupos antraceno terminais do rotaxano.

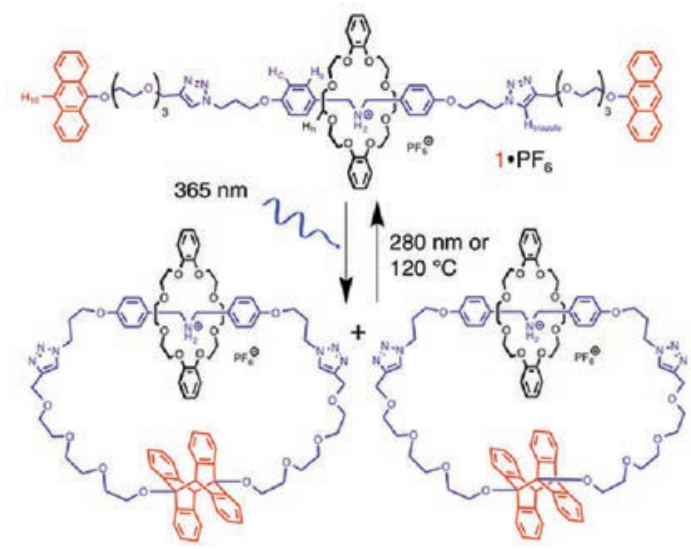

Esta descoberta, dizem os investigadores, pode ser útil para a produção de dispositivos à escala nano com propriedades que possam ser controladas pela luz.

(adaptado de "Light drives unusual rotaxane-to-catenane transformation”, http://www.rsc.org/chemistryworld/2015/01/rotaxane-catenane-transformation-light | Arnaud Tron, Henri-Pierre Jacquot de Rouville, Aurélien Ducrot, James H. R. Tucker, Massimo Baroncini, Alberto Credi, Nathan D. McClenaghan. Chem. Commun. 51 (2015) 2810-2813)

Paulo Mendes (pjgm@uevora.pt) 